JPdK Volume 3 Nomor 2 Tahun 2021 Halaman 85-90

JURNAL PENDIDIKAN dan KONSELING

Research \& Learning in Primary Education

\title{
Analisis Kesulitan dalam Pembelajaran Matematika Berbasis Daring pada Siswa SMP
}

\author{
Harischa Isrothul Jannah', Karima Candra Sari², Rosa Oktaviani ${ }^{3}$, Mila Masruroh ${ }^{4}$ Darmadi $^{5}$ \\ Program Studi Pendidikan Matematika, \\ Fakultas Keguruan dan Ilmu Pendidikan, \\ Universitas PGRI Madiun
}

Email: harischa04@gmail.com, andrasariya@ gmail.com, rosaoktaviani65@gmail.com, milamasruroh56@gmail.com, darmadi7868482@yahoo.com

\begin{abstract}
Abstrak
Pandemi COVID-19 berlangsung sejak Maret 2020 yang berdampak di berbagai bidang, tak terkecuali bidang pendidikan. Selama masa pandemi sistem pembelajaran tatap muka diubah menjadi pembelajaran dirumah atau daring. Pada saat pembelajaran daring banyak siswa mengalami kesulitan dan kendala dalam proses pelaksanaannya, khususnya di mata pelajaran matematika. Penelitian ini dilakukan oleh mahasiswa semester 6 program studi pendidikan matematika Universitas PGRI Madiun. Tujuan dari penelitian ini adalah untuk mengetahui kesulitan siswa dalam pembelajaran matematika berbasis daring pada tingkatan siswa sekolah menengah pertama (SMP). Metode penelitian ini yaitu deskriptif kualitatif dengan teknik pengumpulan data melalui survey angket online yang disebarkan melalui WhatsApp. Berdasarkan hasil analisis angket online dapat disimpulkan bahwa siswa mampu menggunakan media pembelajaran dengan baik namun kendala umum yang dialami siswa yaitu kurang memadainya jaringan internet yang mengakibatkan siswa kurang maksimal dalam pembelajaran matematika berbasis daring. Kendala lain dalam proses pembelajaran daring yaitu siswa sering merasa bosan, penjelasan guru sulit dipahami serta soal matematika yang diberikan sulit yang mengakibatkan siswa tidak mandiri dalam mengerjakan tugas dan siswa mengikuti les tambahan maematika agar lebih mudah memahami materi.
\end{abstract}

Kata Kunci: Kesulitan, Matematika, Daring.

\begin{abstract}
The COVID-19 pandemic has been going on since March 2020 which has had an impact on various fields, including education. During the pandemic, the face-to-face learning system was changed to learning at home or online. During online learning, many students experience difficulties and obstacles in the implementation process, especially in mathematics. This research was conducted by 6th semester students of the mathematics education study program at PGRI Madiun University. The purpose of this study was to determine the difficulties of students in online-based mathematics learning at the junior high school (SMP) level. This research method is descriptive qualitative with data collection techniques through online questionnaire surveys distributed via WhatsApp. Based on the results of the online questionnaire analysis, it can be concluded that students are able to use learning media well, but a common obstacle experienced by students is the inadequate internet network which causes students to be less than optimal in online-based mathematics learning. Another obstacle in the online learning process is that students often feel bored, the teacher's explanations are difficult to understand and the math problems given are difficult which results in students not being independent in doing assignments and students taking additional mathematics lessons to make it easier to understand the material.
\end{abstract}

Keywords: Difficulty, Math, Online. 


\section{PENDAHULUAN}

Pendidikan pada hakekatnya adalah sebauh proses untuk menyiapkan manusia agar dapat bertahan dalam lingkungannya (life skill) (Asmara, 2016). Matematika merupakan salah satu cabang ilmu pengetahuan yang dipelajari di sekolah. Pelajaran matematika tidak melulu tentang angka, tetapi jauh lebih dalam dari itu. Banyak kemampuan yang bisa dikembangkan dari pembelajaran matematika, antara lain penyelesaian masalah, komunikasi matematis, dan koneksi matematis (Puspaningtyas, 2019). Akan tetapi, pelajaran matematika ini dirasa sulit, kurang menarik dan dianggap membosankan oleh beberapa siswa. Selain itu peristiwa yang sering terjadi dalam pembelajaran matematika adalah kurangnya aktif siswa dalam kegiatan belajar mengajar, kurang berpartisipasi dalam pelajaran matematika dan siswa hanya terkesan sebaagi pendengar saja sesuai apa yang telah dijelaskan atau diinformasikan oleh guru. Hal ini bisa terjadi karena dipicu oleh mayoritas guru yang masih menggunakan pembelajaran konvensional, seperti metode ceramah. Padahal seharusnya guru itu merupakan perencana pembelajaran yang baik dan dituntut harus mampu merancang sistem pembelajaran dengan memanfaatkan berbagai jenis sumber dan media pembelajaran yang sesuai dengan kurikulum yang digunakan agar dalam proses kegiatan pembelajaran berjalan dengan efektif dan efisien.

Sejak diumumkan pemerintah mengenai kasus pertama Coronavirus Disease 2019 (Covid-19) pada bulan Maret 2020 yang lalu, Indonesia kemudian dihadapkan pada masa pandemi. Hampir seluruh vektor kehidupan terdampak, tidak terkecuali di sektor pendidikan. Covid-19 ini menular begitu cepat dan telah menyebar ke seluruh penjuru negara, sehinggan Badan Kesehatan Dunia (WHO) menjadikan wabah ini sebagai pandemi global pada tanggal 11 Maret 2020 (Asmuni, 2020).

Pembelajaran daring ialah sebuah pembelajaran yang dilakukan secara jarak jauh berbantuan media berupa internet dan alat perangkat penunjang lainnya seperti telepon seluler, laptop dan komputer (Putria et al., 2020). Artinya, bahwa penggunaan pembelajaran daring melibatkan unsur teknologi sebagai sarana dan jaringan sebagai sistem (Fitriyani et al., 2020). Pembelajaran daring sangat berbeda dengan pembelajaran biasanya. Selama pembelajaran daring berlangsung banyak orang tua yang mengeluh dengan berbagai masalah yang dialami oleh siswa selama belajar dari rumah, diantaranya adalah terlalu banyak tugas yang diberikan oleh guru yang belum mengoptimalkan mengenai teknologi dengan baik. Disamping banyaknya keluhan dari orang tua ternyata dalam pembelajaran daring memiliki beberapa kelebihan yaitu banyaknya waktu dan tempat untuk belajar, misalnya belajar bisa dilakukan di kamar, ruang tamu dan sebagainya serta untuk waktunya bisa menyesuaikan keadaan misalnya pagi, siang, sore ataupun malam hari. Selain itu juga bisa mengatasi permasalahan bagi siswa yang jarak rumahnya jauh jadi siswa tidak harus pergi ke sekolahan bisa belajar langsung dari rumah, sehingga bisa menghemat biaya transportasi dan banyak wawasan yang luas. Adapun kekurangan dari pembelajaran daring yaitu berkurangnya interaksi antara siswa dengan guru, keterbatasan internet, kurangnya pemahaman terhadap materi dan minimnya pengawasan dalam belajar. Menurut (Amallia \& Unaenah, 2018) mengatakan bahwa masih banyak siswa yang menganggap matematika itu sebagai pelajaran yang sulit, sehingga menyebabkan siswa mudah menyerah sebelum mempelajari matematika. Apalagi, dengan adanya pembelajaran daring yang terkesan mendadak akibat pandemi covid-19 ini menyebabkan persiapan untuk melakukan kegiatan pembelajaran tidak optimal. Sehingga dapat menyebabkan siswa tidak siap dalam pelaksanaan kegiatan pembelajarannya, terutama dalam bidang mata pelajaran matematika.

Berdasarkan penjelasan uraian diatas, maka diperlukan untuk melakukan suatu kajian mengenai keadaan dan kesulitan yang dihadapi oleh siswa pada mata pelajaran matematika saat pembelajaran daring yang dilaksanakan oleh sekolah menengah pertama (SMP). Maka dari itu, tujuan dari penilitian diatas yaitu untuk menganalisis kesulitan belajar matematika saat pembelajaran daring pada siswa SMP.

\section{METODOLOGI PENELITIAN}

Subjek pada penelitian ini adalah siswa SMP dari beebrapa SMP yang berada di daerah Madiun dan Ponorogo. Untuk daerah Madiun antara lain SMPN 3 Madiun, SMPN 5 Madiun, SMPN 7 Madiun, MTsN Kota Madiun, SMPN 1 Mejayan, dan SMPN 3 Saradan, sedangkan untuk daerah Ponorogo yaitu dari SMPN 1 Sampung. Penelitian ini dilakukan pada tanggal 10 Juni 2021 sampai 16 Juni 2021 dilaksanakan secara daring. Metode yang digunakan pada penelitian ini adalah metode kualitatif.

Secara garis besar pengertian penelitian kualitatif adalah penelitian yang bertujuan memahami fenomena yang dialami oleh subyek penelitian (Shidiq \& Choiri, 2019). Menurut (Ghony \& Almanshur, 2012) dalam (Shidiq \& Choiri, 2019) contoh fenomena yang dialami oleh subyek antara lain perilaku, persepsi, motivasi, tindakan, dan sebagainya, secara holistik dengan cara deskriptif dalam suatu konteks khusus yang alami tanpa ada campur tangan manusia 
dan dengan memanfaatkan secara optimal sebagai metode ilmiah yang lazim digunakan.

Teknik yang digunakan dalam pengumpalan data ini adalah dengan menggunakan angket, dimana nantinya akan didapat data yang berbentuk kuantitafif dari hasil angket tersebut. Berikut adalah angket yang digunakan untuk penelitian ini:

Table 1. Angket pernyataan kesulitan dalam pembelajara matematika

\begin{tabular}{|c|c|c|c|c|c|c|}
\hline \multirow[t]{2}{*}{ No. } & \multirow[t]{2}{*}{ Pernyataan } & \multicolumn{5}{|c|}{ Pilihan Jawaban } \\
\hline & & SS & $\mathrm{S}$ & RR & $\mathrm{TS}$ & ST \\
\hline 1. & $\begin{array}{l}\text { Saya selalu } \\
\text { mempersiapk } \\
\text { an buku } \\
\text { pelajaran } \\
\text { matematika } \\
\text { sebelum } \\
\text { pelajaran } \\
\text { daring } \\
\text { dimulai }\end{array}$ & & & & & \\
\hline 2 . & $\begin{array}{l}\text { Guru } \\
\text { memberikan } \\
\text { media } \\
\text { pembelajaran } \\
\text { (zoom/googl } \\
\text { e } \\
\text { meet/google } \\
\text { classroom/ms } \\
\text {.teams/WA) }\end{array}$ & & & & & \\
\hline 3. & $\begin{array}{l}\text { Saat guru } \\
\text { memberikan } \\
\text { materi saya } \\
\text { mempelajarin } \\
\text { ya dengan } \\
\text { baik }\end{array}$ & & & & & \\
\hline 4. & $\begin{array}{l}\text { Selam } \\
\text { pembelajaran } \\
\text { daring saya } \\
\text { sering } \\
\text { terkendala } \\
\text { sinyal }\end{array}$ & & & & & \\
\hline 5. & $\begin{array}{l}\text { Saya belajar } \\
\text { matematika } \\
\text { jika situasi } \\
\text { memungkink } \\
\text { an }\end{array}$ & & & & & \\
\hline 6. & $\begin{array}{l}\text { Saya kurang } \\
\text { maksimal } \\
\text { dalam } \\
\text { pembelajaran } \\
\text { matematika } \\
\text { berbasis } \\
\text { daring karena } \\
\text { saya tidak } \\
\text { mahir dalam } \\
\text { menggunaka } \\
\text { n aplikasi } \\
\text { berbasis } \\
\text { daring }\end{array}$ & & & & & \\
\hline
\end{tabular}

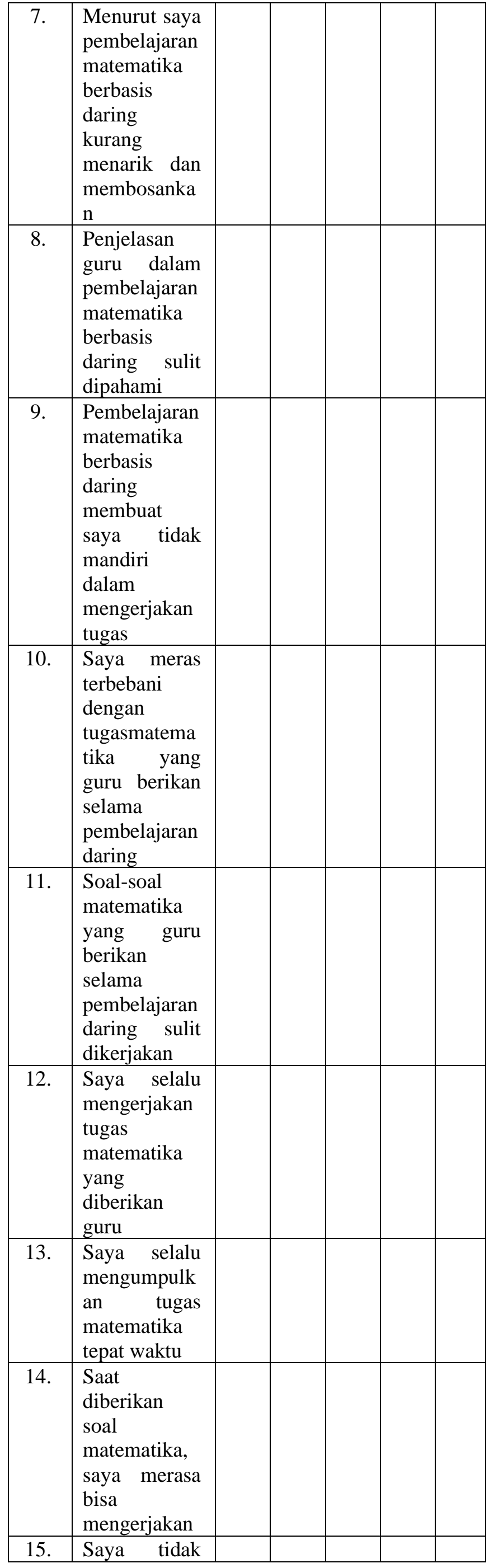




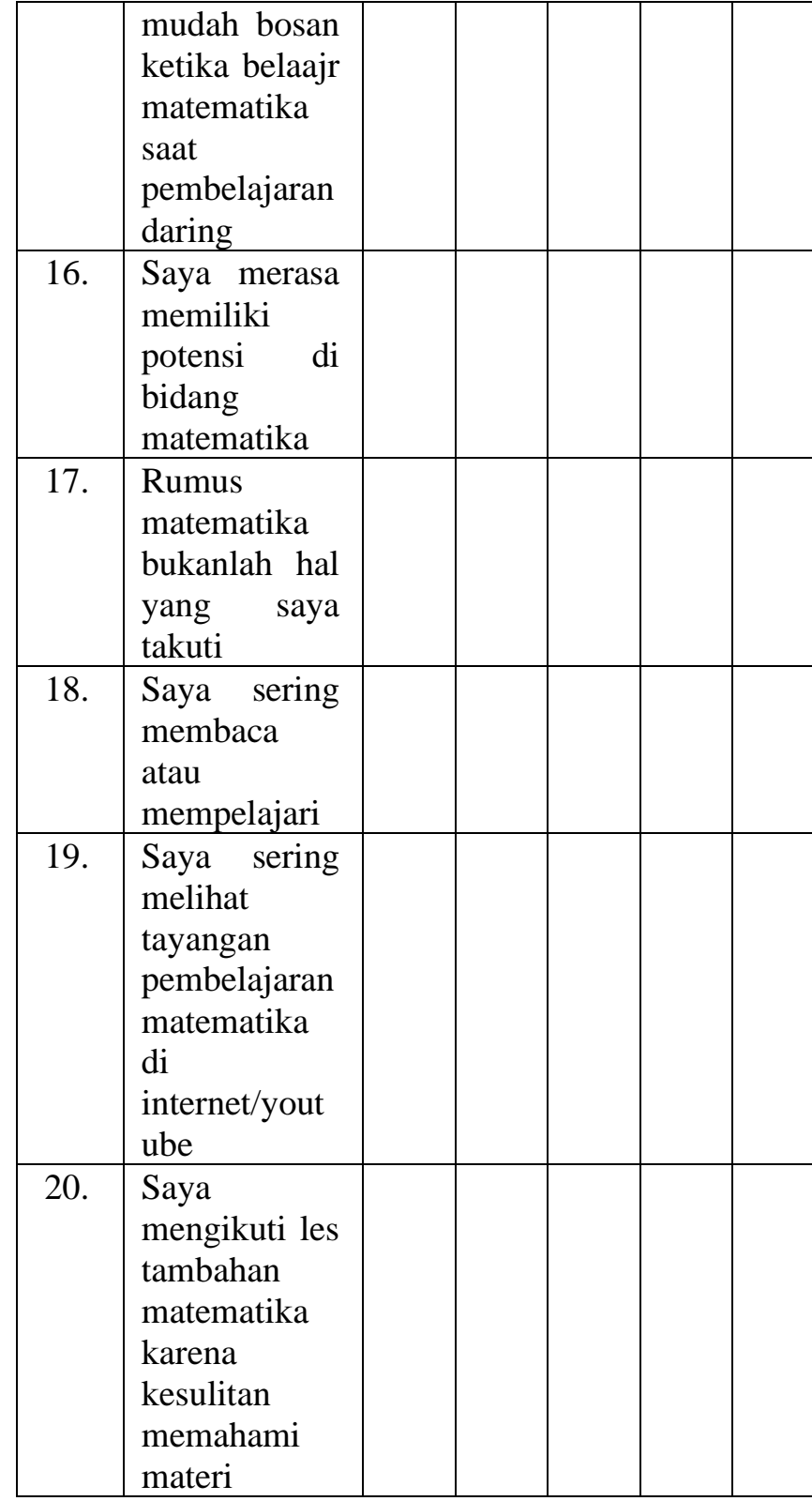

Keterangan:

$$
\begin{array}{ll}
\text { SS } & \text { : Sangat Setuju } \\
\text { S } & : \text { Setuju } \\
\text { RR } & : \text { Ragu - Ragu } \\
\text { TS } & \text { : Tidak Setuju } \\
\text { ST } & \text { : Sangat Tidak Setuju }
\end{array}
$$

Table 2. Skor pernyataan angket kesulitan dalam pembelajaran matematika

\begin{tabular}{|c|c|c|}
\hline $\begin{array}{c}\text { Pilihan } \\
\text { jawaban }\end{array}$ & $\begin{array}{c}\text { Skor } \\
\text { (positif) }\end{array}$ & $\begin{array}{c}\text { Skor } \\
\text { (negatif) }\end{array}$ \\
\hline SS & 5 & 1 \\
\hline S & 4 & 2 \\
\hline RR & 3 & 3 \\
\hline TS & 2 & 4 \\
\hline ST & 1 & 5 \\
\hline
\end{tabular}

Setelah diketahui hasil dari pengisian angket tersebut kemudian menentukan klasifikasi motivasi belajar dimana menurut (Jatmiko, 2015) dihitung berdasarkan menentukan rerata (X) seluruh skor angket siswa, menentukan simpangan baku (2) seluruh skor angket siswa, dan terakhir menentukan klasifikasinya dimana tabelnya adalah sebagai berikut:

Table 3. Pedoman klasifikasi motivasi belajar

\begin{tabular}{|l|c|}
\hline \multicolumn{1}{|c|}{ Klasifikasi } & Skor \\
\hline $\begin{array}{l}\text { Motivasi sangat } \\
\text { tinggi }\end{array}$ & $\overline{\mathrm{X}}+3 \partial \leq$ skor \\
\hline Motivasi tinggi & $\overline{\mathrm{X}}+\partial \leq$ skor $<\overline{\mathrm{X}}+3 \partial$ \\
\hline Motivasi cukup & $\overline{\mathrm{X}}-\partial \leq$ skor $<\overline{\mathrm{X}}+\partial$ \\
\hline Motivasi rendah & $\overline{\mathrm{X}}-3 \partial \leq$ skor $<\overline{\mathrm{X}}-\partial$ \\
\hline $\begin{array}{l}\text { Motivasi sangat } \\
\text { rendah }\end{array}$ & skor $<\overline{\mathrm{X}}-3 \partial$ \\
\hline
\end{tabular}

\section{HASIL PENELITIAN DAN PEMBAHASAN}

Penelitian ini mencakup serangkaian yang dialami responden mengenai kesulitan belajar matematika dengan membandingkan hasil survey serta teori yang telah ada. Penelitian ini dilakukan secara online dengan cara disebarkannya google form kepada siswa SMP. Penelitian ini memiliki delapan belas jumlah responden dengan tingkat subjek sangat tinggi, subjek tinggi, subjek sedang dan subjek rendah. Berdasarkan penelitian ini menjelaskan analisis kesulitan dalam pembelajaran matematika berbasis daring. Subjek tinggi diartikan bahwa siswa mengalami kesulitan dalam pembelajaran matematika berbasis daring dibandingkan dengan subjek sedang dan rendah. Angket kesulitan belajar pembelajaran matematika yang sudah diberikan kepada delapan belas siswa SMP memperoleh hasil sebagai berikut:

Table 4. Hasil angket kesulitan dalam pembelajaran

\begin{tabular}{|l|l|l|l|l|l|l|l|l|l|l|}
\hline \multirow{2}{*}{$\begin{array}{l}\text { Nama } \\
\text { Siswa }\end{array}$} & \multicolumn{10}{|c|}{ Pertanyaan ke- } \\
\cline { 2 - 11 } & 1 & 2 & 3 & 4 & 5 & 6 & 7 & 8 & 9 & 10 \\
\hline WA & 4 & 4 & 4 & 2 & 4 & 2 & 2 & 2 & 2 & 2 \\
\hline KN & 3 & 4 & 3 & 4 & 2 & 3 & 1 & 1 & 4 & 4 \\
\hline YD & 4 & 4 & 4 & 2 & 3 & 3 & 2 & 3 & 2 & 2 \\
\hline FH & 3 & 4 & 3 & 3 & 1 & 4 & 2 & 2 & 2 & 2 \\
\hline MA & 4 & 4 & 4 & 4 & 3 & 4 & 2 & 2 & 2 & 4 \\
\hline SA & 3 & 5 & 4 & 4 & 2 & 3 & 1 & 1 & 1 & 4 \\
\hline ZA & 2 & 2 & 3 & 4 & 2 & 3 & 1 & 1 & 1 & 4 \\
\hline MD & 3 & 5 & 3 & 2 & 3 & 1 & 1 & 2 & 1 & 2 \\
\hline KF & 3 & 3 & 3 & 3 & 1 & 2 & 1 & 1 & 1 & 2 \\
\hline AH & 3 & 4 & 2 & 2 & 2 & 2 & 1 & 1 & 2 & 2 \\
\hline NW & 5 & 5 & 4 & 2 & 1 & 3 & 2 & 1 & 2 & 2 \\
\hline FS & 3 & 4 & 3 & 2 & 1 & 4 & 1 & 1 & 1 & 4 \\
\hline MN & 4 & 4 & 4 & 2 & 2 & 4 & 4 & 2 & 4 & 4 \\
\hline CF & 3 & 4 & 5 & 5 & 2 & 4 & 2 & 2 & 5 & 2 \\
\hline RA & 3 & 4 & 3 & 3 & 2 & 4 & 3 & 2 & 2 & 2 \\
\hline KA & 3 & 4 & 2 & 5 & 2 & 3 & 1 & 1 & 1 & 1 \\
\hline
\end{tabular}




\begin{tabular}{|l|l|l|l|l|l|l|l|l|l|l|}
\hline TA & 5 & 5 & 4 & 3 & 2 & 1 & 1 & 1 & 1 & 1 \\
\hline TC & 5 & 5 & 5 & 5 & 1 & 5 & 1 & 1 & 1 & 1 \\
\hline
\end{tabular}

Table 5. Lanjutan tabel 4, hasil angket kesulitan belajar

\begin{tabular}{|l|l|l|l|l|l|l|l|l|l|l|}
\hline Nama & \multicolumn{10}{|c|}{ Piswa } \\
\cline { 2 - 12 } & 11 & 12 & 13 & 14 & 15 & 16 & 17 & 18 & 19 & 20 \\
\hline WA & 2 & 4 & 3 & 3 & 2 & 2 & 2 & 3 & 3 & 4 \\
\hline KN & 3 & 4 & 4 & 3 & 2 & 3 & 2 & 1 & 4 & 2 \\
\hline YD & 3 & 4 & 4 & 3 & 3 & 3 & 4 & 3 & 4 & 4 \\
\hline FH & 3 & 2 & 2 & 5 & 2 & 1 & 3 & 1 & 5 & 2 \\
\hline MA & 3 & 4 & 3 & 3 & 4 & 3 & 3 & 3 & 3 & 2 \\
\hline SA & 5 & 5 & 5 & 3 & 3 & 2 & 3 & 2 & 3 & 1 \\
\hline ZA & 2 & 4 & 3 & 3 & 2 & 2 & 5 & 4 & 4 & 2 \\
\hline MD & 1 & 2 & 2 & 2 & 1 & 3 & 2 & 1 & 3 & 1 \\
\hline KF & 2 & 3 & 3 & 3 & 2 & 4 & 3 & 4 & 3 & 2 \\
\hline AH & 2 & 3 & 3 & 3 & 2 & 3 & 3 & 3 & 3 & 2 \\
\hline NW & 2 & 3 & 3 & 3 & 3 & 3 & 3 & 3 & 3 & 3 \\
\hline FS & 1 & 3 & 3 & 2 & 2 & 3 & 3 & 2 & 2 & 5 \\
\hline MN & 4 & 4 & 3 & 4 & 4 & 3 & 4 & 4 & 3 & 2 \\
\hline CF & 1 & 3 & 5 & 4 & 1 & 3 & 3 & 4 & 3 & 5 \\
\hline RA & 1 & 4 & 3 & 3 & 3 & 3 & 3 & 3 & 4 & 2 \\
\hline KA & 1 & 3 & 2 & 1 & 1 & 2 & 2 & 1 & 1 & 2 \\
\hline TA & 2 & 4 & 3 & 3 & 3 & 3 & 2 & 4 & 4 & 3 \\
\hline TC & 1 & 4 & 5 & 2 & 1 & 1 & 2 & 1 & 1 & 3 \\
\hline
\end{tabular}

Berdasarkan hasil perhitungan rata-rata dan simpangan baku dari hasil angket, diperoleh klasifikasi kesulitan belajar pelajaran matematika disajikan pada tabel sebagai berikut :

Table 6. Klasifikasi motivasi belajar

\begin{tabular}{cc}
\hline Klasifikasi & Skor \\
\hline Kesulitan Sangat Tinggi & $54,2 \leq$ skor \\
Kesulitan Tinggi & $51,6 \leq$ skor $<54,2$ \\
Kesulitan Cukup & $48.9 \leq$ skor $<51,6$ \\
Kesulitan Rendah & $46,2 \leq$ skor $<48,9$ \\
Kesulitan Sangat Rendah & Skor $<46,9$ \\
\hline
\end{tabular}

Hasil perhitungan berdasarkan klasifikasi nilai angket kesulitan belajar pelajaran matematika yang telah diisi oleh delapan belas siswa, disajikan pada diagram sebagai berikut:

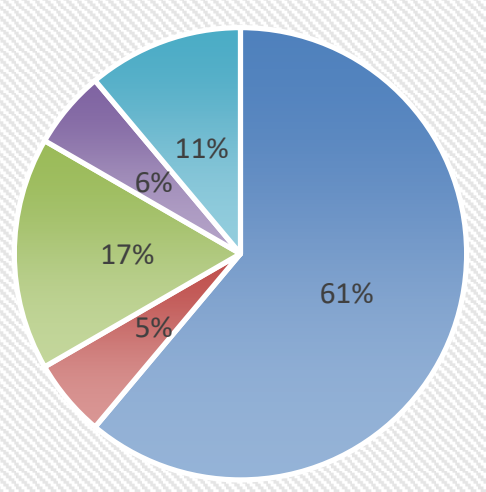

- Kesulitan

Sangat Tinggi

- Kesulitan

Tinggi

- Kesulitan

Cukup

- Kesulitan

Rendah

- Kesulitan

Sangat Rendah

\section{Figure 1. Hasil angket dan klasifikasi kesulitan belajar}

Berdasarkan diagram diatas diperoleh hasil siswa dengan kesulitan sangat tinggi yaitu $61 \%$ atau sebelas siswa, siswa dengan kesulitan tinggi yaitu 5\% atau sebanyak satu Siswa, siswa dengan kesulitan cukup yaitu $17 \%$ atau sebanyak tiga siswa, siswa dengan kesulitan rendah yaitu 6\% atau sebanyak satu siswa, siswa dengan kesulitan sangat rendah yaitu $11 \%$ atau sebanyak dua siswa.

Siswa dengan kesulitan belajar menjadi jumlah terbanyak dibandingkan dengan kategori siswa yang tidak mengalami kesulitan/kesulitan sangat rendah karena banyaknya kendala yang dialami siswa seperti contohnya siswa sering terkendala sinyal, penjelasan guru sulit dipahami yang mengakibatkan siswa terbebani dalam mengerjakan soal matematika yang diberikan oleh guru. Karena hal tersebut siswa akhirnya tidak mengerjakan tugas secara mandiri, namun hanya ada sedikit siswa yaitu sebanyak empat orang melakukan les tambahan matematika. Faktor kendala lain dalam pelajaran matematika berbasis daring yatu siswa merasa bosan ketika pembelajaran daring dimulai serta media yang diberikan oleh guru kurang menarik.

Siswa dengan kesulitan belajar sangat rendah/tidak mengalami kesulitan menyukai belajar di rumah di karenakan waktu lebih fleksibe, selain itu siswa mencari referensi lebih luas seperti di laman youtube, internet serta buku pelajaran matematika. Karena pembelajaran daring siswa tidak bisa bertatap muka dengan guru akibatnya interaksi antara siswa dan guru kurang maksimal maka siswa mengikuti les tambahan matematika agar lebih mudah memahami materi yang diberikan oleh guru.

\section{SIMPULAN}

Simpulan pada penelitian yang bertujuan untuk menganalisis kesulitan dalam pembelajaran matematika berbasis daring pada siswa SMP adalah siswa terbagi dalam lima kategori yaitu siswa dengan kesulitan sangat tinggi, siswa dengan kesulitan tinggi, siswa dengan kesulitan cukup, siswa dengan kesulitan rendah, siswa dengan kesulitan sangat rendah. Berdasarkan data 
menunjukkan siswa dengan kesulitan sangat tinggi di posisi terbanyak, di karenakan sulitnya memahami materi matematika saat pembelajaran daring serta kurangnya semangat siswa dalam mempelajari matematika secara mandiri.

\section{DAFTAR PUSTAKA}

Amallia, N., \& Unaenah, E. (2018). Analisis Kesulitan Belajar Matematika Pada Siswa Kelas III Sekolah Dasar. Attadib Journal Of Elementary Education, 3(2), 123-133. https://www.jurnalfaiuikabogor.org/index.php/attadib/article/view/41 4

Asmara, A. S. (2016). Peningkatan Kemampuan Pemecahan Masalah Dan Disposisi Matematis Siswa Smk Dengan Pembelajaran Berbasis Masalah Berbantuan Multimedia Interactive. Jurnal Sekolah Dasar, 1(1), 31-39. https://doi.org/10.36805/jurnalsekolahdasar.v1i 1.59

Asmuni, A. (2020). Problematika Pembelajaran Daring di Masa Pandemi Covid-19 dan Solusi Pemecahannya. Jurnal Paedagogy, 7(4), 281. https://doi.org/10.33394/jp.v7i4.2941

Fitriyani, Y., Fauzi, I., \& Sari, M. Z. (2020). Motivasi Belajar Mahasiswa Pada Pembelajaran Daring Selama Pandemik Covid-19. Profesi Pendidikan Dasar, 7(1), 121-132. https://doi.org/10.23917/ppd.v7i1.10973

Jatmiko. (2015). Hubungan Motivasi Belajar dengan Hasil Belajar Matematika Siswa Kelas X SMK Nahdhatul Ulama Pace Nganjuk. Math Educator Nusantara, 01(02), 205-213. file://C:/Users/USER/Downloads/Documents/2 37-49-620-1-10-20160204.pd

Puspaningtyas, N. D. (2019). Berpikir Lateral Siswa SD dalam Pembelajaran Matematika. Mathema Journal, 1(1), 24-30.

Putria, H., Maula, L. H., \& Uswatun, D. A. (2020). Analisis Proses Pembelajaran dalam Jaringan (DARING) Masa Pandemi Covid- 19 Pada Guru Sekolah Dasar. Jurnal Basicedu, 4(4), 861-870.

https://doi.org/10.31004/basicedu.v4i4.460

Shidiq, U., \& Choiri, M. (2019). Metode Penelitian Kualitatif di Bidang Pendidikan. In Journal of Chemical Information and Modeling (Vol. 53, Issue 9). http://repository.iainponorogo.ac.id/484/1/MET ODE PENELITIAN KUALITATIF DI BIDANG PENDIDIKAN.pdf 